\title{
Efficiency of Interproximal Reduction Technique for Correction of Anterior Crowding without Extraction: A Case Report
}

\author{
Ike Sesaria and Ida Bagus Narmada
}

Department of Orthodontic, Faculty of Dental Medicine, Universitas Airlangga, Surabaya, Indonesia

\begin{abstract}
Crowding is one of the most common findings in orthodontic patients. This case report describes the correction of anterior crowding with interproximal reduction (IPR). The case is that of a 24 -year-old female patient who consulted for irregularly placed anterior teeth. Fixed appliances were placed followed by IPR. Treatment time was 18 months. Class I molar relation was maintained, with normal overjet and overbite. IPR is effective for treatment of patients with Class I malocclusion with anterior moderate crowding.
\end{abstract}

Key Words: crowding, interproximal reduction, non-extraction

\section{INTRODUCTION}

Malocclusion is a worldwide dental problem that influences the affected individuals to varying degrees. ${ }^{1}$ It is defined as an abnormal occlusion in which the teeth are not in a normal position in relation to adjacent teeth in the same jaw or to the opposing teeth when the jaws are closed. ${ }^{2}$ The effect of malocclusion is not only functional or aesthetic; it also has a psychosocial impact due to the demands of today's world. ${ }^{2}$

Dental crowding, especially in the anterior region, is one of the most common findings in orthodontic patients. ${ }^{3}$ Proffit and McDonald had suggested that crowding and malalignment were due primarily to inherited tendencies that determine facial proportions and soft tissue contour as well as teeth and jaw size. Mild and moderate degree of malalignment might be present even in the absence of habits or environmental factors, however extremely severe crowding probably has genetic component as well as environmental component. ${ }^{4}$

In orthodontic treatment the main goal of the orthodontist is to create a balance among occlusal relationships, dental and facial aesthetics, and thus achieving a long-term treatment stability. ${ }^{3}$

Interproximal enamel reduction (IPR), also described

Paper presented at the Joint Scientific Meeting in Special Care Dentistry, July 5, 2019, Amerta Room, 4th Floor, main campus of Universitas Airlangga, Surabaya, Indonesia.

Corresponding author: Ida Bagus Narmada

Department of Orthdontic

Faculty of Dental Medicine

Universitas Airlangga

J. Mayjen. Prof. Dr. Moestopo No. 47 Surabaya 60132 - Indonesia

Email: dr_narmada@yahoo.com as "stripping", "reproximation" and "slenderizing", dates back to 1944 , when it was first advocated for correcting lack of tooth size harmony; this was done by stripping the proximal surfaces of the mandibular anterior segment. ${ }^{5}$

Indications for interproximal enamel reduction include mild or moderate crowding in dental arches, when the lack of space in the dental arch is 4 to $8 \mathrm{~mm}$, Bolton Index discrepancy, elimination of black gingival triangles, and for 
post treatment prophylaxis in the prevention of potential crowding during retention. ${ }^{3,6}$

\section{CASE REPORT}

A 24-year-old, Javanese female patient came to the Orthodontic Clinics of UNAIR Dental Hospital with the chief complaint of irregularly placed anterior teeth and unaesthetic smile. She had no other pertinent medical history.

Extraoral examination revealed mesocephalic and symmetrical face and convex profile with competent lips. She presented with retroclined upper incisors with gummy smile (Figure 1). There was no displacement in the mandibular path of closure (Figure 2).
Intraoral examination revealed normal mucosa, gingiva, tongue size, and frenulum attachments. She presented as a person with good oral hygiene. She had moderate crowding in both arches and retroclination of the upper incisors (Figure 2). The lower arch was square shaped.

Dental model analysis showed that the patient had $5 \mathrm{~mm}$ upper arch and $6.5 \mathrm{~mm}$ lower arch discrepancy, the molar relationship was Angle Class I, and canine relationship was Class I on the left side and edge-to edge on the right side. Other findings included overjet of $1 \mathrm{~mm}$, overbite of $4.5 \mathrm{~mm}$, and positive curve of Spee. There was no midline shift.

Radiographic examination (Figure 3) revealed the presence of all permanent dentition. Cephalometric evaluation (Table 1) revealed skeletal Class I, high
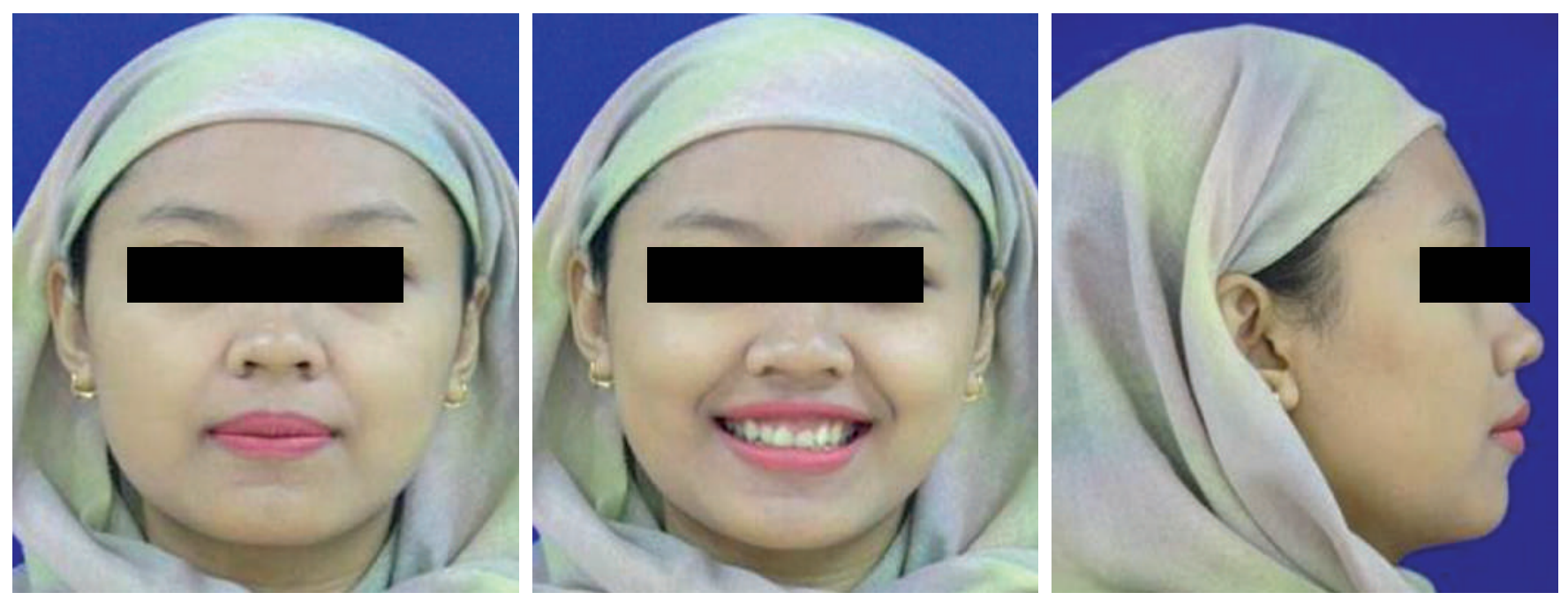

Figure 1. Extraoral facial profile pre-treatment.
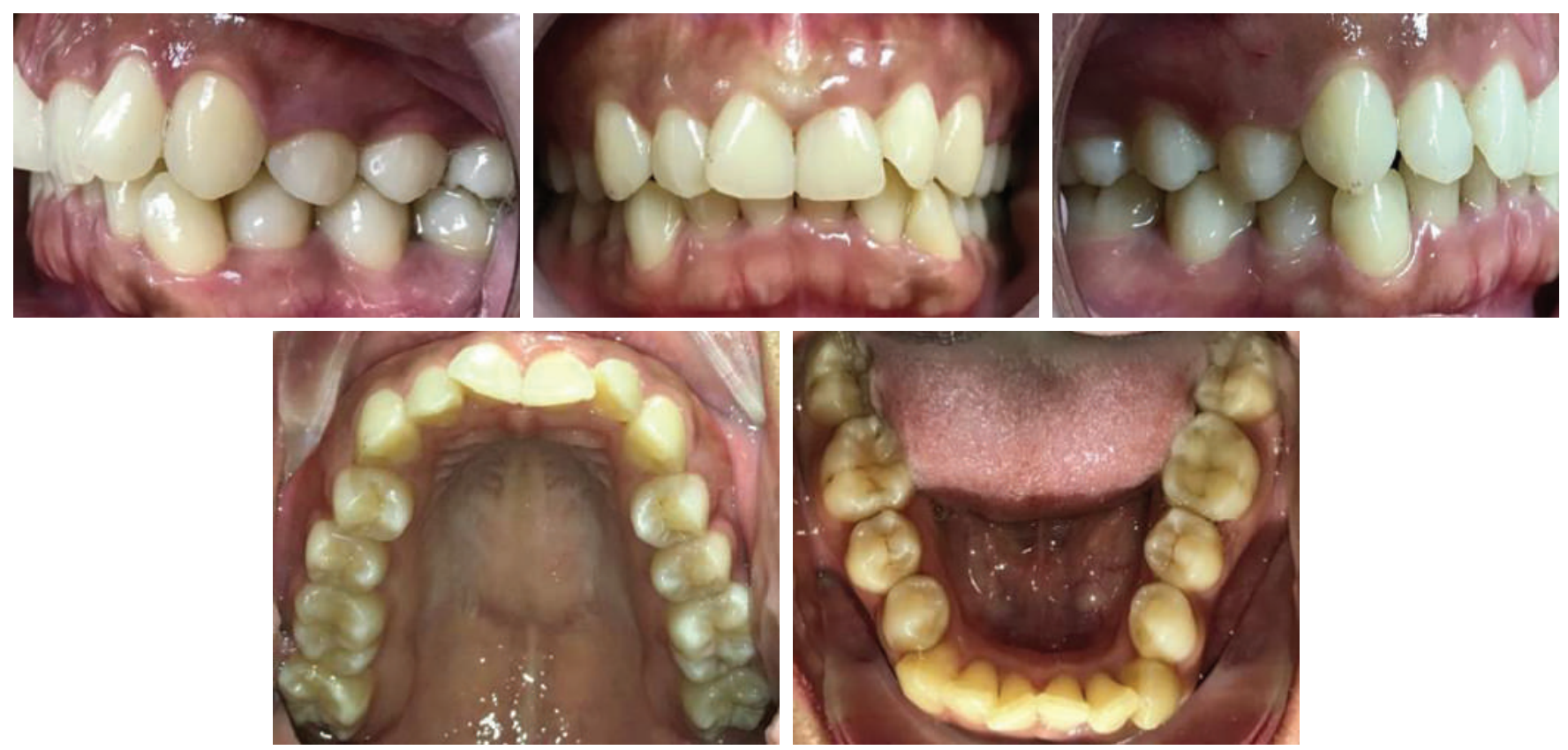

Figure 2. Intraoral pre-treatment. 

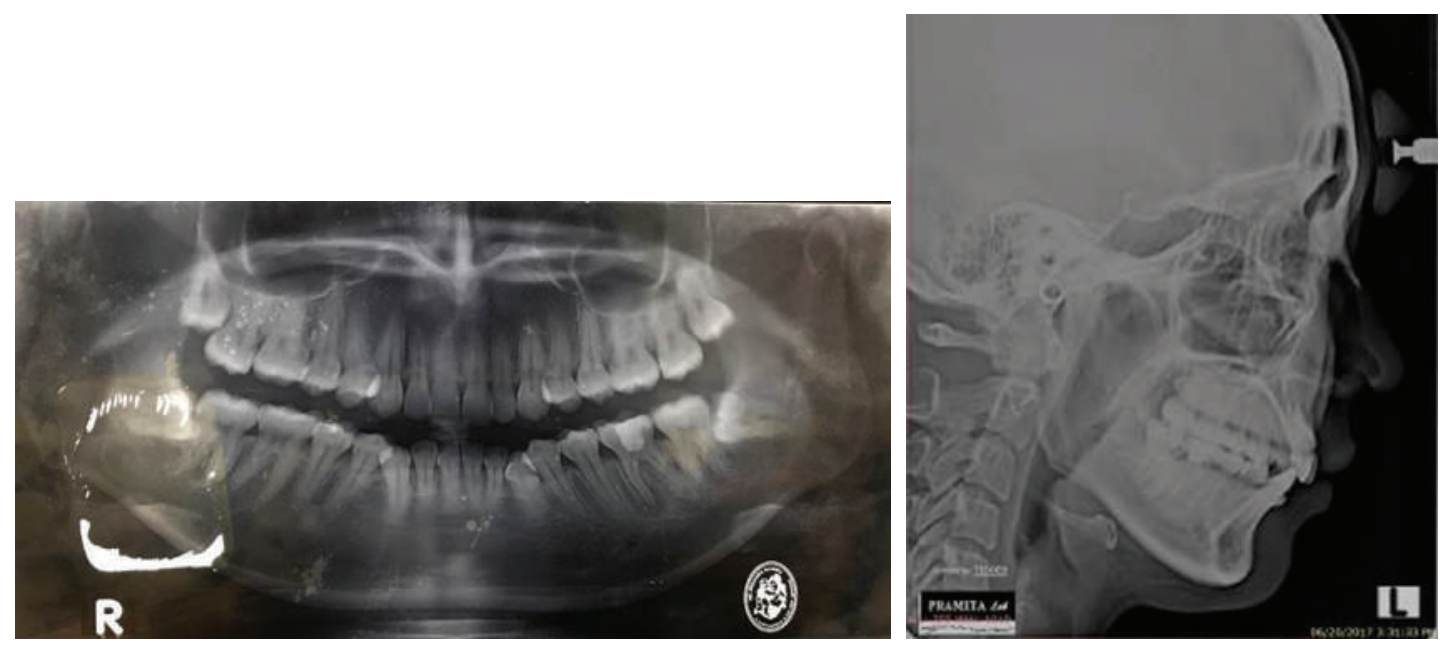

Figure 3. X-rays pre-treatment.

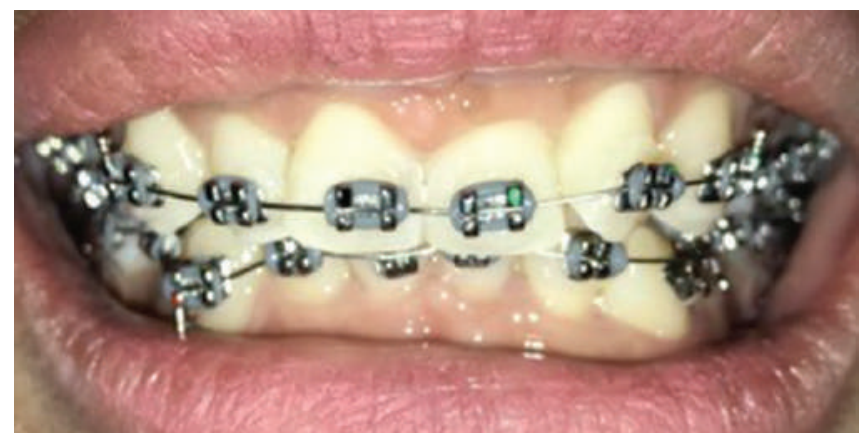

Figure 4. Levelling and aligning (0.012" NiTi).

mandibular angle, and protrusive upper and lower lips. Final diagnosis was Angle Class I malocclusion with moderate upper and lower anterior crowding and deep bite.

The patient was treated using preadjusted appliance system (American Orthodontics, Sheboygan, WI USA) with slot size 0.022 " $\times 0.028$ " Roth prescription (upper and lower metal brackets) and buccal tubes. Treatment was started with levelling and unraveling (Figure 4). Upper and lower 0.012" NiTi, 0.014" NiTi, and then 0.016" NiTi wires were engaged for initial levelling and alignment. After levelling and alignment was achieved, treatment with IPR in the four upper and six lower anterior teeth was done using slow-speed contra-angle handpiece with files (IPR almighty) (Figure 5). Subsequent to this, upper and lower 0.016 " x 0.016 " NiTi followed by $0.016 " \times 0.022$ "
Table 1. Cephalometric analysis

\begin{tabular}{|c|c|c|}
\hline Variable & Pre-treatment & Post-treatment \\
\hline FH-NPog & 81 & 81 \\
\hline $\mathrm{FH}-\mathrm{MP}$ & 32 & 32 \\
\hline$N A-P_{0}(\mathrm{deg})$ & 4 & 4 \\
\hline $\mathrm{SNA}_{(\mathrm{deg})}$ & 78,5 & 78,5 \\
\hline $\mathrm{SNB}_{(\mathrm{deg})}$ & 75 & 75 \\
\hline $\mathrm{ANB}_{(\mathrm{deg})}$ & 3,5 & 3,5 \\
\hline Wits appraisal AO-BO & 1,5 & 1,5 \\
\hline U1-NA ${ }_{(\mathrm{deg})}$ & 23 & 23 \\
\hline $\mathrm{L} 1-\mathrm{NB}_{(\mathrm{deg})}$ & 28 & 30 \\
\hline \multirow{2}{*}{ Ricket's Lip analysis } & $\begin{array}{l}\text { Upper lip 0,5mm } \\
\text { in front of } E \text { line }\end{array}$ & $\begin{array}{l}\text { Upper lip } 2 \mathrm{~mm} \\
\text { behind } E \text { line }\end{array}$ \\
\hline & $\begin{array}{l}\text { Lower lip } 1 \mathrm{~mm} \text { in } \\
\text { front of } E \text { line }\end{array}$ & $\begin{array}{l}\text { Lower lip 0,5mm } \\
\text { behind } \mathrm{E} \text { line }\end{array}$ \\
\hline
\end{tabular}

$\mathrm{NiTi}$ wires were placed. This was followed by upper and lower $0.017 " \times 0.025 " \mathrm{NiTi}$ wires followed by use of class II intermaxillary elastics (16-20 oz - 3/16").

The Angle Class I molar and canine relationship was maintained and normal overjet $(2 \mathrm{~mm})$ and overbite $(2 \mathrm{~mm})$ were achieved (Figure 7); this was followed by finishing and detailing and arch coordination. The treatment was completed with ideal archwires. Both arches showed good alignment. Deep bite was corrected, with flat curve of Spee. No root resorption was noticed (Figure 8). Upper and lower lip position was significantly decreased (Figure 6). The total
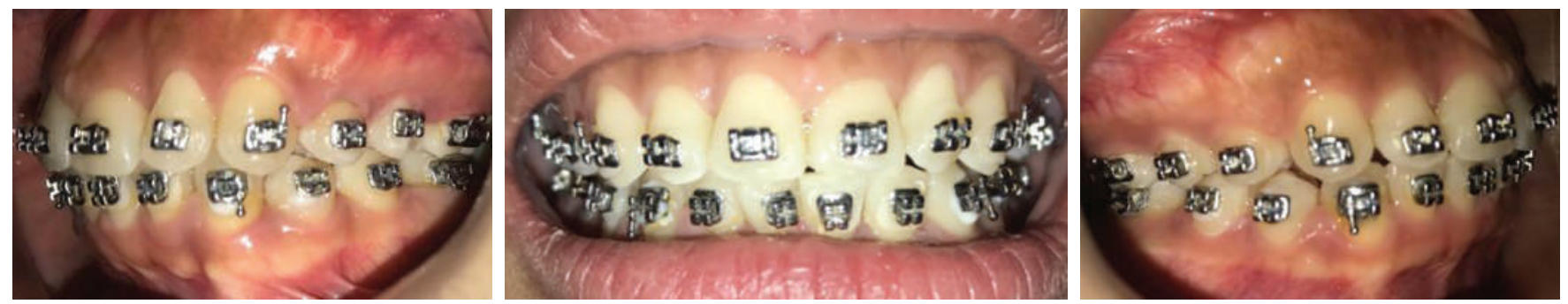

Figure 5. Intraoral after IPR. 

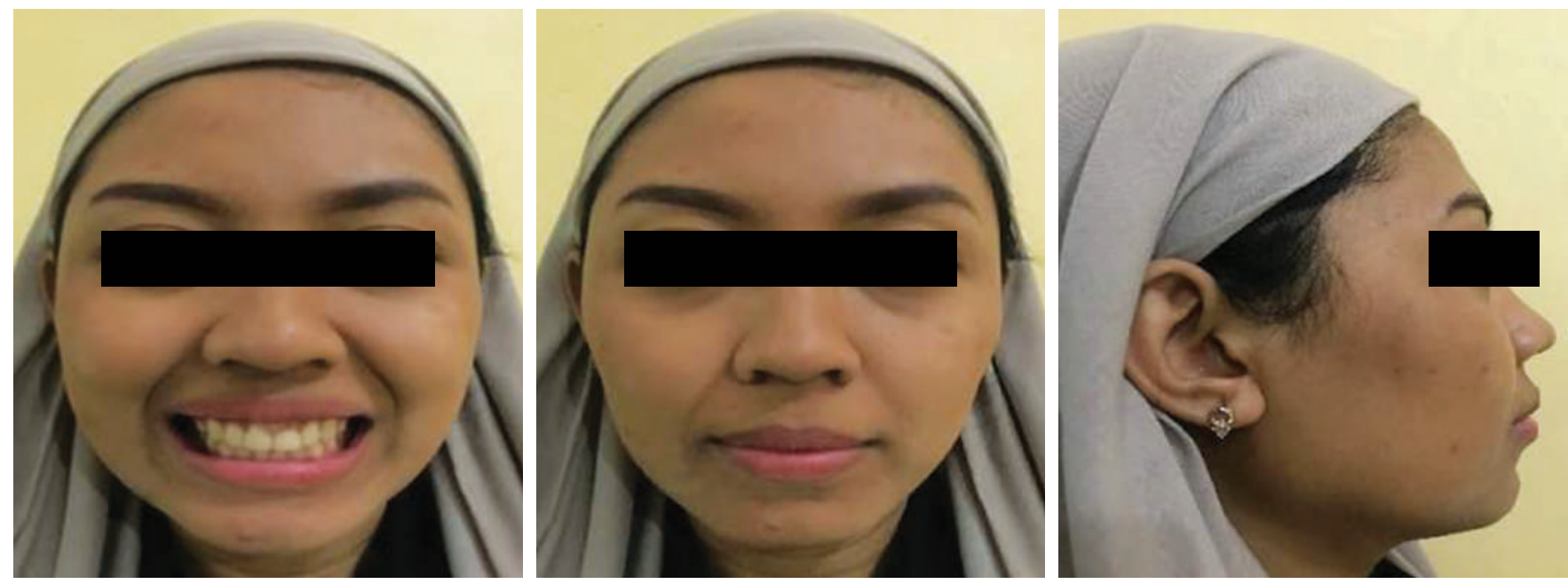

Figure 6. Extraoral facial profile post-treatment.
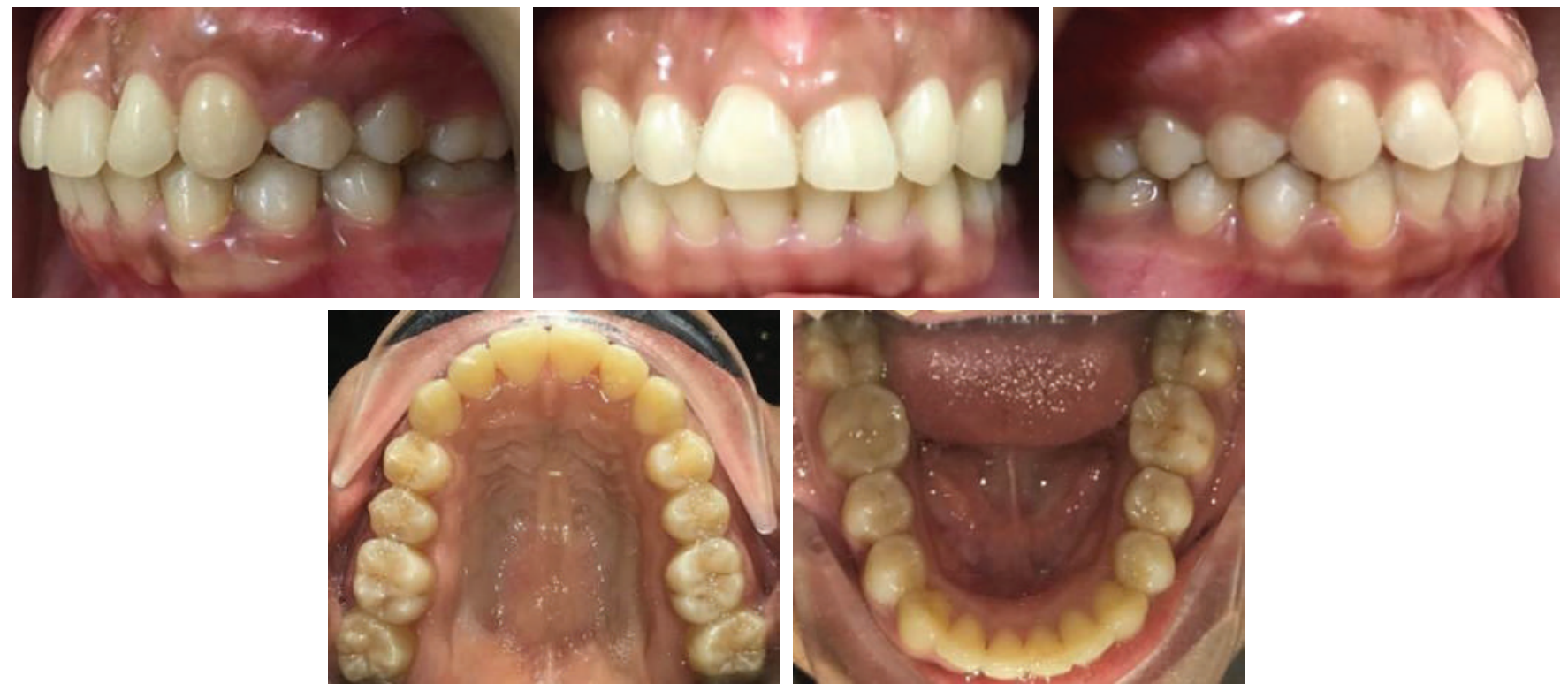

Figure 7. Intraoral post-treatment.
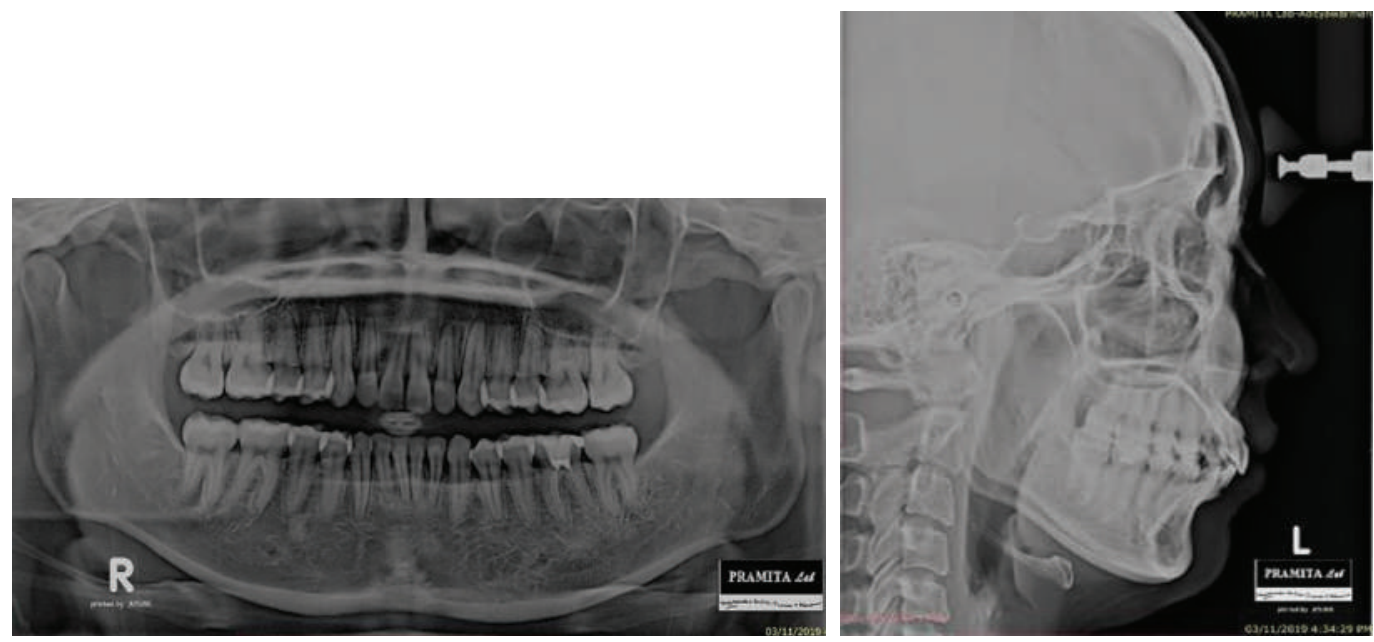

Figure 8 . X-rays post-treatment. 
duration of active treatment was 18 months. Maxillary retention consisted of Hawley retainer type and mandibular retention with wrap-around retainer type.

\section{DISCUSSION}

Very few dental malocclusions are encountered where there is an excess of space. For the resolution of a majority of malocclusions, space is required. For achieving majority of the treatment objectives, space has to be created within the jaws. ${ }^{7}$

Several methods are suggested for relieving dental crowding such as transverse arch expansion, proclination of the anterior teeth, distalization of the teeth in the arch, extraction of the tooth, or interproximal enamel reduction. The age of the patient, facial profile, and amount of crowding determine the choice of the treatment strategy. ${ }^{3}$

The reason for choosing the type of treatment extraction or non-extraction is arch discrepancy. In this case, the patient had $5 \mathrm{~mm}$ upper arch and $6.5 \mathrm{~mm}$ lower arch discrepancy. For arch length discrepancy of $10 \mathrm{~mm}$ or more, extraction almost always is required. ${ }^{8}$ Cephalometric evaluation and soft tissue examination are also done. Extraction is not required for all cases.

Management of moderate crowding by IPR can lead to well aligned arches without extraction of any permanent tooth and yet gain the required space. ${ }^{9}$

The most common techniques to correct anterior crowding include several methods such as conventional handheld abrasive strips, discs, diamond coated strips, slow-speed contra-angle handpiece with files, burs, and mechanical rotary systems. ${ }^{9}$

In this case, we used slow-speed contra-angle handpiece with files (almighty set, Cina). These are thin, semi-flexible strips used with a holder. This technique requires more time than Air Rotor Stripping with bur, but the results obtained are more predictable, and the enamel surface obtained is smoother than that achieved when using burs. ${ }^{3}$

The most frequently stripped teeth are the mandibular incisors. The maxillary anterior teeth can be stripped where the enamel thickness is sufficient. ${ }^{7}$

It is recommended that up to $50 \%$ of interproximal enamel can be removed during IPR. The appropriate amount should be $0.5 \mathrm{~mm}(0.25 \mathrm{~mm}$ each side $)$ for each tooth whereas up to $0.75 \mathrm{~mm}$ for posterior teeth may be removed. With $50 \%$ of enamel reduction per tooth, up to 8.6 $\mathrm{mm}$ space can be created by IPR of the mandibular teeth. ${ }^{6}$

The advantages of IPR are decreased treatment time, prevention of interdental gingival retraction, and less tooth movement. ${ }^{10}$ IPR can also create space for better alignment, minimize potential problems with extraction therapy, and thus allow self-retention. ${ }^{6,10}$

IPR should not be carried out in patients with a high risk for caries and in those with poor oral hygiene to avoid the risk of development of caries. The major contraindications are crowding of more than $8 \mathrm{~mm}$ per arch, active periodontal diseases, enamel hypoplasia, hypersensitivity to cold, multiple restorations, and round-shaped premolar. ${ }^{3}$

Class II elastics are used from the lower first molar to the upper canine tooth. They can be used for many different reasons, in this case, to allow the maxillary incisors to move backwards. ${ }^{11}$

In this case, dental crowding was corrected in both arches. It is commonly expected that orthodontic treatments can increase the quality of life in people affected with malocclusion.

\section{CONCLUSION}

IPR is an important part of orthodontic treatment for gaining space in the dental arch to improve tooth and gingival aesthetics. IPR is effective in patients with Class I malocclusion with moderate anterior lower crowding. In our patient, the Class I molar and canine relationship was maintained and normal overjet and overbite were achieved. Deep bite was corrected. Upper and lower lip position was significantly decreased. The total duration of active treatment was 18 months. Retention consisted of Hawley retainer type in the maxilla and clear retainer type in the mandible. Orthodontists should choose appropriate indications for IPR by balancing its benefits and risks for specific patients.

\section{Acknowledgments}

We thank the patient and Airlangga University Dental Hospital for the consent to use the photographs and for this case to be presented, respectively.

\section{Statement of Authorship}

All authors participated in data collection and analysis, and approved the final version submitted.

\section{Author Disclosure}

All authors declared no conflict of interest.

\section{Funding Source}

None.

\section{REFERENCES}

1. Zou J, Meng M, Law CS, Rao Y, Zhou X. Common dental diseases in children and malocclusion. Int J Oral Sci. 2018 Mar; 10(1):7.

2. Pelaez AN, Itati GL, Mazza SM. The need for orthodontic treatment according to severity of malocclusion in adult patients [Internet]. 2015 [cited 2019 May] Available from: http://www.scielo.edu.uy/pdf/ ode/v17n26/v17n26a03.pdf.

3. Choudhary A, Gautman AK, Chousky A, Bhusan M, Nigam N, Tiwari M. Interproximal enamel reduction in orthodonyic treatment: A review. JOADMS. 2015; 1(3):123-7.

4. Ibrahim HA, Abuaffan AH. Prevalence of Malocclusion and Orthodontic Treatment Needs in Down Syndrome Sudanese Individuals. Orthod J Nepal. 2014; 4(2):32-7.

5. Kolge NE. Interproximal Reduction: A Twin Helix Device. jpjournals. 2018;10031-1233:112-4. 
6. Chee D, Ren C, Yang Y. An overview on interproximal enamel reduction. Dent Open J. 2014; 1(1):14-8

7. Singh G. Textbook of Orthodontics, Second ed. New Delhi: Jaypee Medical Publishers; 2015. pp. 234-235.

8. Proffit WR, Fields HW, Larson B SD. Contemporary Orthodontics, 6th ed. St. Louis: Mosby Elsevier; 2018. p. 209.

9. Alam M, Imran A, Shahid F, Nowrin S. Minor tooth movement for crowding and anterior crossbite: A pictorial case report. Int J Pharma Bio Sci. 2015; 6(3):1207-14.
10. Barcoma E, Shroff B, Best AM, Shoff MC, Lindauer SJ. Interproximal reduction of teeth : Differences in perspective between orthodontists and dentists. Angle Orthod. 2015 Sep; 85(5):820-5.

11. Janson G, Sathler R, Fernandes TM, Branco NC, Freitas MR. Correction of Class II malocclusion with Class II elastics: a systematic review. Am J Orthod Dentofacial Orthop. 2013 Mar; 143(3):383-92. 